\section{Vorfeldanalytik, toxikologische}

T. Arndt

Bioscientia Institut für Medizinische Diagnostik $\mathrm{GmbH}$, Ingelheim, Deutschland

Definition Bezeichnung für die schnelle, mitunter vor Ort durchgeführte, zumeist qualitative oder semiquantitative
Analyse von z. B. Atemluft, Blut- oder Urinproben, auch Medikamentenrückständen auf Drogen, Pharmaka oder sonstige Giftstoffe.

Beschreibung Beispiele hierfür sind der $\triangleright$ Drogennachweis mit Teststreifen im Urin oder mit sog. Wischtests im Achselschweiß, Atemalkoholkontrollen und der Nachweis von gasförmigen oder leicht flüchtigen Verbindungen mit DrägerPrüfröhrchen. 